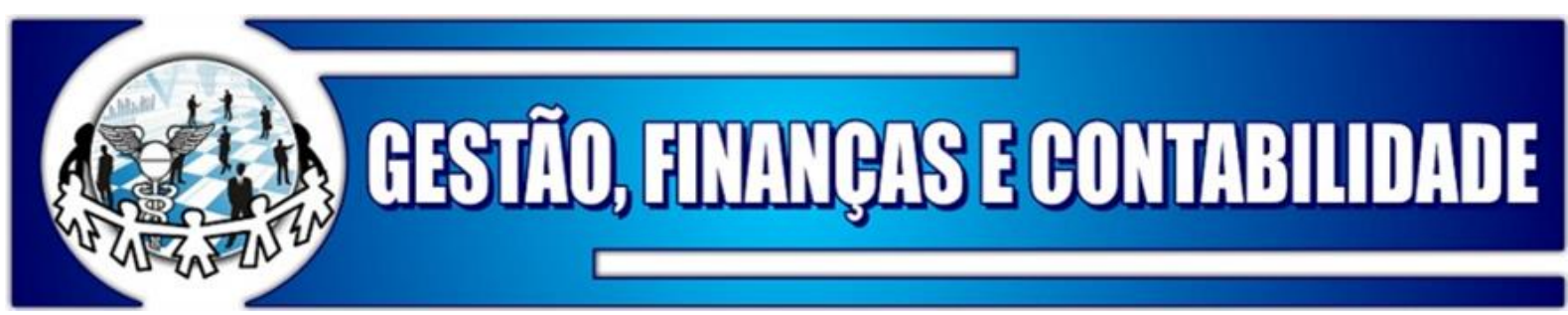

\title{
INFLUÊNCIA DO CETICISMO PROFISSIONAL NO GERENCIAMENTO DE IMPRESS ̃̃O DA DIVULGAÇÃO DA INFORMAÇÃO CONTÁBIL
}

\section{INFLUENCE OF PROFESSIONAL SKEPTICISM ON IMPRESSION MANAGEMENT OF ACCOUNTING INFORMATION DISCLOSURE}

\section{INFLUENCIA DEL ESCEPTICISMO PROFESIONAL EN LA GESTIÓN DE IMPRESIÓN DE LA DIVULGACIÓN DE INFORMACIÓN CONTABLE}

\author{
Daniel Matthes \\ https://orcid.org/0000-0002-0395-4569 \\ Bacharel em Ciências Contábeis pela Universidade do Estado de Santa Catarina (UDESC) \\ E-mail: danielmatthes10@gmail.com \\ Camila Adam \\ https://orcid.org/0000-0001-7404-926X \\ Mestre em Ciências Contábeis pela Universidade Regional de Blumenau (FURB) \\ E-mail: adam.camila11@gmail.com \\ Jules Kout Tene \\ https://orcid.org/0000-0002-0001-9233 \\ Mestre em Ciências Contábeis pela Universidade Regional de Blumenau (FURB) \\ E-mail: tenejules5@yahoo.fr \\ Paulo Roberto da Cunha \\ https://orcid.org/0000-0001-5805-9329 \\ Professor do Programa de Pós-graduação em Ciências Contábeis e Administração da \\ Universidade Regional de Blumenau (PPGCC/FURB) e do Curso de Graduação em Ciências \\ Contábeis da Universidade do Estado de Santa Catarina (UDESC) \\ Doutor em Ciências Contábeis e Administração pela Universidade Regional de Blumenau \\ E-mail:pauloccsa@furb.br
}

\section{RESUMO}

O objetivo do estudo foi analisar a influência do ceticismo profissional sobre o gerenciamento de impressão na divulgação da informação contábil. O ceticismo profissional foi analisado por meio das variáveis mente questionadora, suspensão de julgamento, busca de conhecimento, compreensão interpessoal, autonomia e autoestima, conforme constructo de Hurtt (2010). O gerenciamento de impressão foi analisado por meio das variáveis seletividade, distorção de medição e aprimoramento de divulgação, conforme Cardoso, Leite e Aquino (2018). A pesquisa caracteriza-se como descritiva, survey e quantitativa. A amostra do estudo foi composta por 201 acadêmicos do curso de Ciências Contábeis de duas Universidades Públicas do Estado de Santa 
Influência do Ceticismo Profissional no Gerenciamento de Impressão da Divulgação da Informação Contábil

Catarina. A análise dos dados se deu por meio de estatística descritiva e regressão OLS por meio do software SPSS ${ }^{\circledR}$. Os resultados da pesquisa demonstraram que a característica mente questionadora influencia negativamente as variáveis aprimoramento de divulgação e distorção de medição, demonstrando que quanto maior o nível da característica mente questionadora num indivíduo, menor a possibilidade de este ser influenciado por duas das técnicas de gerenciamento de impressão.

Palavras-chave: Ceticismo profissional; Gerenciamento de impressão; Divulgação da informação contábil.

\begin{abstract}
The paper analyzed the influence of professional skepticism on impression management in the disclosure of accounting information. Professional skepticism was analyzed through the variables questioning mind, suspension of judgment, searching for knowledge, interpersonal understanding, self-confidence and self-determination, according to Hurtt's construct (2010). Impression management was analyzed using selectivity, measurement distortion and presentational enhancement variables, according to Cardoso, Leite and Aquino (2018). The research is characterized as descriptive, survey and quantitative. The study sample consisted of 201 students of the Accounting Sciences course of two Public Universities of the State of Santa Catarina. Data analysis was performed using descriptive statistics and OLS regression using the SPSS $®$ software. The survey results demonstrated that the questioning mind feature negatively influences the presentational enhancement and measurement distortion variables, demonstrating that the higher the level of the questioning mind feature in an individual, the less likely it is to be influenced by two of the impression management techniques.
\end{abstract}

Keywords: Professional Skepticism; Management of Accounting; Information Disclosure.

\title{
RESUMEN
}

El estudio analizó la influencia del escepticismo profesional en la gestión de la impresión en la divulgación de información contable. El escepticismo profesional se analizó a través de las variables cuestionamiento mental, suspensión del juicio, búsqueda de conocimiento, comprensión interpersonal, autonomía y autoestima, según el constructo de Hurtt (2010). La gestión de la impresión se analizó utilizando variables de selectividad, distorsión de medición y mejora de la divulgación, según Cardoso, Leite y Aquino (2018). La investigación se caracteriza por ser descriptiva, encuesta y cuantitativa. La muestra de estudio consistió en 201 estudiantes del curso de Ciencias Contables de dos Universidades Públicas del Estado de Santa Catarina. El análisis de datos se realizó mediante estadística descriptiva y regresión OLS utilizando el software SPSS ${ }^{\circledR}$. Los resultados de la encuesta demostraron que la función de la mente inquisitiva influye negativamente en la mejora de las variables de divulgación y distorsión de la medición, lo que demuestra que cuanto mayor sea el nivel de la función de la mente inquisitiva en un individuo, es menos probable que se vea influenciado por dos de las técnicas de gestión de impresión.

Palabras Clave: Escepticismo profesional; Gestión de impresión; Divulgación de información contable.

\section{INTRODUÇÃO}

A contabilidade e a auditoria têm sofrido críticas devido à vários escândalos envolvendo fraudes financeiras ao redor do mundo desde o início do milênio. Para exemplificar, há o caso 
da Enron nos Estados Unidos entre os anos de 1997 e 2000, período em que superestimou seus lucros em 600 milhões, transferiu bilhões de dívidas e superfaturou a venda de ativos para empresas não controladas e como consequência teve que reajustar os resultados em U\$ 1,25 bilhões (REZAEE, 2005; CUNHA et al., 2019).

Os escândalos corporativos acendem um alerta no público em geral sobre a capacidade da contabilidade em prestar informações sobre a realidade da companhia. Certo nível de insegurança deriva de dúvidas acerca da confiabilidade das informações divulgadas e da capacidade da auditoria em assegurar que os registros contábeis divulgados nas demonstrações contábeis reflitam os fatos ocorridos na companhia (PAYNE; RAMSAY, 2005).

A informação contábil deve ser neutra e seguir determinados requisitos, para que não possa ser utilizada com fim de influenciar o usuário em sua tomada de decisão e evitar que fatos sejam mensurados de acordo com a conveniência da gestão da empresa. Desta forma, as normas contábeis estabelecem que é imprescindível que a informação possua relevância, materialidade e veracidade, requisitos básicos, sendo possível aumentar a sua qualidade por meio de atributos como comparabilidade, verificabilidade, tempestividade e compreensibilidade (COMITE DE PRONUNCIAMENTOS CONTÁBEIS - CPC 00, 2011).

Neste âmbito, diversos estudos têm sido elaborados com o intuito de analisar a qualidade da informação contábil nas demonstrações divulgadas para verificar se atendem ou não aos requisitos exigidos de relevância, materialidade e veracidade (COELHO; NIYAMA; RODRIGUES, 2011; PONTE; OLIVEIRA, 2004). Evidências encontradas têm sugerido que empresas têm utilizado as divulgações contábeis como forma de influenciar o julgamento do usuário, contrariando o requisito de neutralidade exigido na informação contábil (JONES, 2011; CHO; MICHELON; PATTEN, 2012; BARKEMEYER et al., 2014; YANG; LIU, 2018).

Uma das técnicas que pode influenciar o julgamento do usuário por meio das divulgações, tem recebido a denominação de gerenciamento de impressão por parte dos pesquisadores (BEATTIE; JONES, 2000; GODFREY; MATHER; RAMSAY, 2003). O gerenciamento de impressão pode ser definido como o uso de táticas para aprimorar a informação de modo a apresentá-la de uma maneira que influencie os leitores de acordo com a intenção do preparador (GODFREY; MATHER; RAMSAY, 2003), buscando legitimar as ações da empresa com base nas expectativas das partes interessadas (ARANTES; GUSMÃO; COSTA, 2019).

Nessa lógica, para persuadir o usuário da informação, as empresas têm utilizado técnicas de seletividade, distorção de medição e aprimoramento de divulgação para gerenciar as informações contidas nos relatórios contábeis e de administração, relatórios de sustentabilidade, cartas aos acionistas e perfis de rede social (CHO; MICHELON; PATTEN, 2012; BARKEMEYER et al., 2014; VARGAS; ALMEIDA; MARIA JÚNIOR, 2014; YANG; LIU, 2018). Existem evidências de que essas técnicas podem afetar o julgamento e a tomada de decisão dos indivíduos a partir das informações divulgadas (PENNINGTON; TUTTLE, 2009).

O julgamento e a tomada de decisão dos indivíduos são frequentemente relacionados com o conceito do ceticismo, principalmente no campo da auditoria. O ceticismo é uma postura exigida do auditor durante seu exercício profissional pelas normas de auditoria brasileiras e internacionais (NOLDER; KADOUS, 2018; MARÇAL; ALBERTON, 2020). A ausência de ceticismo é considerada uma das principais razões que causam falhas e não percepção de erros na auditoria (CARMICHAEL; CRAIG, 1996). Boa parte das fraudes derivam da incapacidade da auditoria para identificar a manipulação de informações por parte dos gestores (NELSON, 2009), o nível de ceticismo também afeta o julgamento e a tomada de decisão na auditoria (POPOVA, 2012). 
Influência do Ceticismo Profissional no Gerenciamento de Impressão da Divulgação da Informação Contábil

Aminudin e Suryandari (2016), investigaram o efeito do ceticismo profissional e habilidades para detecção de fraudes na informação contábil em auditores da Indonésia. Os resultados indicam que o ceticismo incrementa a relação de influência entre a habilidade para detecção de fraudes e o nível de experiência de auditores, ou seja, quanto mais experiente e mais cético o auditor, maior tende a ser a sua capacidade para detecção de fraudes.

Com o intuito de examinar a influência do ceticismo profissional na percepção ética de alunos de auditoria dos EUA, em relação às tentativas de manipulação de resultados nas demonstrações contábeis, Farag e Elias (2016), encontraram evidências de que alunos com nível mais aguçado de ceticismo classificaram as tentativas de manipulação de resultados como mais antiéticas do que seus colegas.

Sendo assim, nota-se a importância do ceticismo, não apenas na atuação do auditor, mas para os usuários da informação contábil de forma geral, pois elevado nível de ceticismo frente a diversas situações contribui para um melhor julgamento e detecção de erros/fraudes das demonstrações contábeis (CARMICHAEL; CRAIG, 1996; CUNHA et al., 2019).

Conforme o exposto, no ambiente organizacional, as empresas podem optar por gerenciar a impressão das partes interessadas para legitimar sua imagem, ou seja, apresentar as informações de uma maneira que comunique uma realidade positiva (GODFREY; MATHER; RAMSAY, 2003; ARANTES; GUSMÃO; COSTA, 2019). Nesse cenário, as partes interessadas podem ser prejudicadas, caso tomem decisões com base em impressões equivocadas do desempenho de uma empresa. Nesse contexto, o ceticismo pode ser fator determinante para reduzir o poder de influência dos mecanismos de gerenciamento de impressão, pois uma mente questionadora leva os indivíduos a analisar com mais cuidado e cautela as informações que se deparam (STOUGH, 1969; HURTT, 2010). Portanto, com base no exposto, tem-se a seguinte questão de pesquisa, qual a influência do ceticismo profissional sobre o gerenciamento de impressão na divulgação da informação contábil?

O estudo é relevante ao apresentar que o ceticismo é uma característica importante para minimizar os efeitos do gerenciamento de impressão, permitindo que o julgamento dos usuários das informações contábeis tenha menor possibilidade de ser influenciado por artifícios implementados pelas empresas no disclosure das informações contábeis. Além disso, o estudo contribui ao evidenciar que o gerenciamento de impressão a partir de gráficos é um artifício que pode influenciar a impressão dos stakeholdes de uma organização sobre as informações divulgadas e, consequentemente o seu julgamento e tomada de decisão. Nesse sentido, deve-se ter atenção não somente ao conteúdo dos relatórios divulgados, mas também a maneira que são divulgados.

Ademais, o estudo contribui com literatura do ceticismo profissional e do gerenciamento de impressão em âmbito nacional, trazendo novas compreensões e insights para complementar os achados das respectivas áreas. Quanto o ceticismo profissional, adiciona conhecimento a uma literatura que investigou principalmente o estado de humor (SAMPAIO, 2017), o nível de estresse ocupacional (HAVEROTH, 2017), a satisfação no trabalho (ROHENKOHL, 2017) e os traços de personalidade (CUNHA et al., 2019; MARÇAL; ALBERTON, 2020). Em relação ao gerenciamento de impressão, traz novos insights para uma literatura que investigou as narrativas dos relatórios de administração (VARGAS; ALMEIDA; MARIA JÚNIOR, 2014; ARANTES; GUSMÃO; COSTA, 2019) e a reflexão cognitiva (CARDOSO; LEITE; AQUINO, 2018).

\section{REVISÃO DA LITERATURA E HIPÓTESES DE PESQUISA}

O ceticismo profissional é definido pelas normas brasileiras de auditoria como uma "postura que inclui uma mente questionadora e alerta para condições que possam indicar 
possível distorção devido a erro ou fraude e uma avaliação crítica das evidências de auditoria" (NBC TA 200, p. 6, 2016), além de ter sua importância reconhecida e exigida por órgãos internacionais (AMERICAN INSTITUTE OF CERTIFIED PUBLIC ACCOUNTANTS, 2017).

A palavra ceticismo deriva dos termos 'observar com cuidado', 'examinar' e 'considerar' (STOUGH, 1969), ademais, uma pessoa cética é aquela que levanta as questões, busca o significado das coisas, sua base de verdade, questiona tudo, inclusive seus próprios julgamentos (HURTT, 2010). Nelson (2009), acrescenta ainda que o ceticismo é uma perspectiva mental de dúvida constante.

Hurtt (2010), divide o ceticismo em duas categorias: os traços de ceticismo, que compõem a personalidade do indivíduo e possuem um aspecto duradouro e estável e o estado de ceticismo, que representa uma condição temporária do indivíduo e é influenciada pelas variáveis situacionais onde o mesmo se encontra inserido.

Os níveis de ceticismo profissional podem ser medidos a partir do teste de Hurtt (2010), que foi desenvolvido com base nas normas de auditoria, psicologia e comportamento do indivíduo. Esse constructo tem sido empregado na maioria dos estudos sobre o tema devido à sua confiabilidade e facilidade de aplicação (POPOVA, 2012; ROYAEE; NEZHAD; AZINFAR, 2013; FARAG; ELIAS, 2016; CUNHA et al., 2019; MARÇAL; ALBERTON, 2020).

Portanto, por meio da definição do ceticismo e suas implicações no comportamento do indivíduo, é possível observar a necessidade e influência do ceticismo profissional na tomada de decisão e julgamento dos indivíduos, pois, uma pessoa com baixo nível de ceticismo está sujeita a erros em sua análise, podendo até mesmo colocar em dúvida suas conclusões (AMINUDIN; SURYANDARI, 2016).

Diante disto, nota-se a relação entre o ceticismo profissional e o gerenciamento de impressão, pois pessoas menos céticas tendem a aceitar uma informação sem questioná-la, o que pode prejudicar a interpretação da divulgação das informações contábeis, quando estas forem elaboradas com técnicas de gerenciamento de impressão (JONES, 2011; CHO; MICHELON; PATTEN, 2012; BARKEMEYER et al., 2014; AMINUDIN; SURYANDARI, 2016; YANG; LIU, 2018).

Assim, no âmbito corporativo, pode-se definir o gerenciamento de impressão como a forma com que as empresas divulgam sua informação de modo a apresentá-la de uma maneira que influencie o leitor ou distorça o real sentido da mensagem (GODFREY; MATHER; RAMSAY, 2003; VARGAS; ALMEIDA; MARIA JÚNIOR, 2014). Pois as principais características que as companhias visam proteger ou aprimorar por meio dos relatórios são: a reputação, que representa o status da companhia; a imagem, que denota os aspectos individuais; a visão do público e a legalidade ou adequação às normas (MERKL-DAVIES; BRENNAN, 2011; ARANTES; GUSMÃO; COSTA, 2019).

O gerenciamento é feito por meio de várias técnicas, das quais as mais utilizadas são, a seletividade (MELO; GRAHAM; NOLAND, 2009), o aprimoramento de divulgações e a distorção de medições (MERKL-DAVIES; BRENNAN, 2011).

A seletividade é definida como a maneira com que as informações são pré-selecionadas nas divulgações, optando-se por divulgar apenas dados de cunho positivo em sua maioria, dificultando a distinção entre os resultados bons e ruins e apresentando uma tendência a interpretação positiva (MELO; GRAHAM; NOLAND, 2009).

$\mathrm{O}$ aprimoramento das divulgações pode ser definido como o uso de afirmações e uma ênfase no aspecto positivo da informação, de modo que a torne melhor apresentável ao público e influencie na interpretação de acordo com o viés do elaborador (MERKL-DAVIES; 
Influência do Ceticismo Profissional no Gerenciamento de Impressão da Divulgação da Informação Contábil

BRENNAN; MCLEAY, 2011). A cor vermelha pode ser associada à sinais negativos, agressividade e intimidação (PRYKE, 2009), em contrapartida, a cor azul está associada a ganhos e uma performance positiva.

A distorção de medição envolve a manipulação de medidas e escalas nos gráficos, seja por meio de mudanças na altura ou largura dos eixos, tais gráficos podem produzir julgamentos imprecisos (CLEVELAND; MCGILL, 1985).

A literatura acerca do gerenciamento de impressão tem se expandido e dividido em várias ramificações, abordando o estudo não apenas das demonstrações contábeis, mas nos demais relatórios e divulgações públicas das companhias, tais como relatórios de sustentabilidade (CHO; MICHELON; PATTEN, 2012), redes sociais (YANG; LIU, 2017) e cartas aos acionistas (HOOGHIEMSTRA, 2010). Outro fator a se atentar é que as empresas estão mais propensas a tentarem manipular a tomada de decisões por meio dos relatórios não obrigatórios, pois estes não possuem um modelo específico e estão mais abertos para a discricionariedade (COURTIS, 2004). Nesta perspectiva é que se entende que o gerenciamento de impressão e o ceticismo profissional possam guardar relação na medida em um indivíduo com traço cético mais desenvolvido, tenha condições de identificar possíveis tentativas ou discricionariedades que possam comprometer a informação contábil.

No que que concerne o ceticismo profissional, Hurtt (2010) identificou seis traços que o definem, sendo a mente questionadora, a suspensão do julgamento, a busca de conhecimento, o conhecimento interpessoal, a autonomia e a autoestima. As características, mente questionadora, suspensão do julgamento e busca do conhecimento fazem referência à maneira de buscar e interpretar os fatos, por outro lado, conhecimento interpessoal, diz respeito à capacidade de avaliar ações e comportamentos e autonomia e autoestima fazem referência ao comportamento do indivíduo frente às informações obtidas (HURTT, 2010).

A mente questionadora pode ser definida como um perfil questionador, busca constante por informações e evidências, além de analisar os dados com cuidado e considerar todos os pontos antes da tomada de decisão (NELSON, 2009). Esse traço é derivado de dúvidas, que dão início a um processo de inquérito das informações, questionar tudo, e a partir de então leva à formação do julgamento do indivíduo (HURTT, 2010). Nesse ensejo apresenta-se a primeira hipótese de pesquisa:

$H_{1}$ : Há uma relação negativa entre a característica do ceticismo profissional mente questionadora e o gerenciamento de impressão da divulgação da informação contábil.

A suspensão do julgamento é o comportamento de aguardar a tomada de decisão até que se tenha determinado nível de provas e evidências que sirvam de base (HURTT, 2010). O indivíduo não deve simplesmente aceitar as afirmações e pedidos, mas ao invés, possuir uma mente aberta para que permita enxergar a situação de forma crítica e por meio de evidências (NELSON, 2009). Sendo assim, apresenta-se a segunda hipótese desta pesquisa:

\section{$\mathrm{H}_{2}$ : Há uma relação ne gativa entre a característica do ceticismo profissional suspensão do julgamento e o gerenciamento de impressão da divulgação da informação contábil.}

A busca de conhecimento caracteriza-se por possuir um senso de curiosidade e interesse pelas coisas, não somente pelo objeto que enseja a dúvida, mas no sentido amplo, o desejo de aprender coisas novas (HURTT, 2010). Dada esta característica de curiosidade e interesse de aprendizado, percebe-se que a mesma se alinha a característica de ceticismo profissional e se contrapõe a perspectiva de gerenciamento de impressão, o que possibilita expor a terceira hipótese de pesquisa: 
Influência do Ceticismo Profissional no Gerenciamento de Impressão da Divulgação da Informação Contábil

$H_{3}$ : Há uma relação negativa entre a característica do ceticismo profissional busca de conhecimento e o gerenciamento de impressão da divulgação da informação contábil.

A compreensão interpessoal diz respeito às habilidades do indivíduo para compreender as motivações e comportamentos de terceiros envolvidos, tais como motivações que possam levar a fraudes, mentiras e informações com viés (HURTT, 2010). Ter esta habilidade desenvolvida pode contribuir para perceber possível tentativa de gerenciamento de impressão, o que remete a quarta hipótese de pesquisa:

H4: Há uma relação negativa entre a característica do ceticismo profissional compreensão interpessoal e o gerenciamento de impressão da divulgação da informação contábil.

A característica de ceticismo profissional autonomia considera a necessidade de avaliar as informações de forma independente e sem a influência de terceiros, permitindo assim que o indivíduo decida por si mesmo se algo é relevante ou não (HURTT, 2010). Tal característica possibilita apresentar a quinta hipótese de pesquisa:

$H_{5}$ : Há uma relação negativa entre a característica do ceticismo profissional autonomia e o gerenciamento de impressão da divulgação da informação contábil.

A autoestima é o sentimento de valorização e crença nas habilidades próprias do indivíduo e, inclusive, a falta de autoestima está relacionada à suscetibilidade de influência na tomada de decisão por terceiros (HURTT, 2010). Entende-se que esta característica pode guardar uma relação inversa com o gerenciamento de impressão na medida que quanto mais desenvolvida tal característica no indivíduo, menor a possibilidade de este não perceber o gerenciamento na informação contábil. Sendo assim, a sexta hipótese de pesquisa é formada:

H6: Há uma relação negativa entre a característica do ceticismo profissional autoestima e o gerenciamento de impressão da divulgação da informação contábil.

Na Figura 1, apresenta-se o modelo conceitual deste estudo, que mostra a relação proposta pela hipótese e as variáveis utilizadas.

Figura 1 - Modelo conceitual

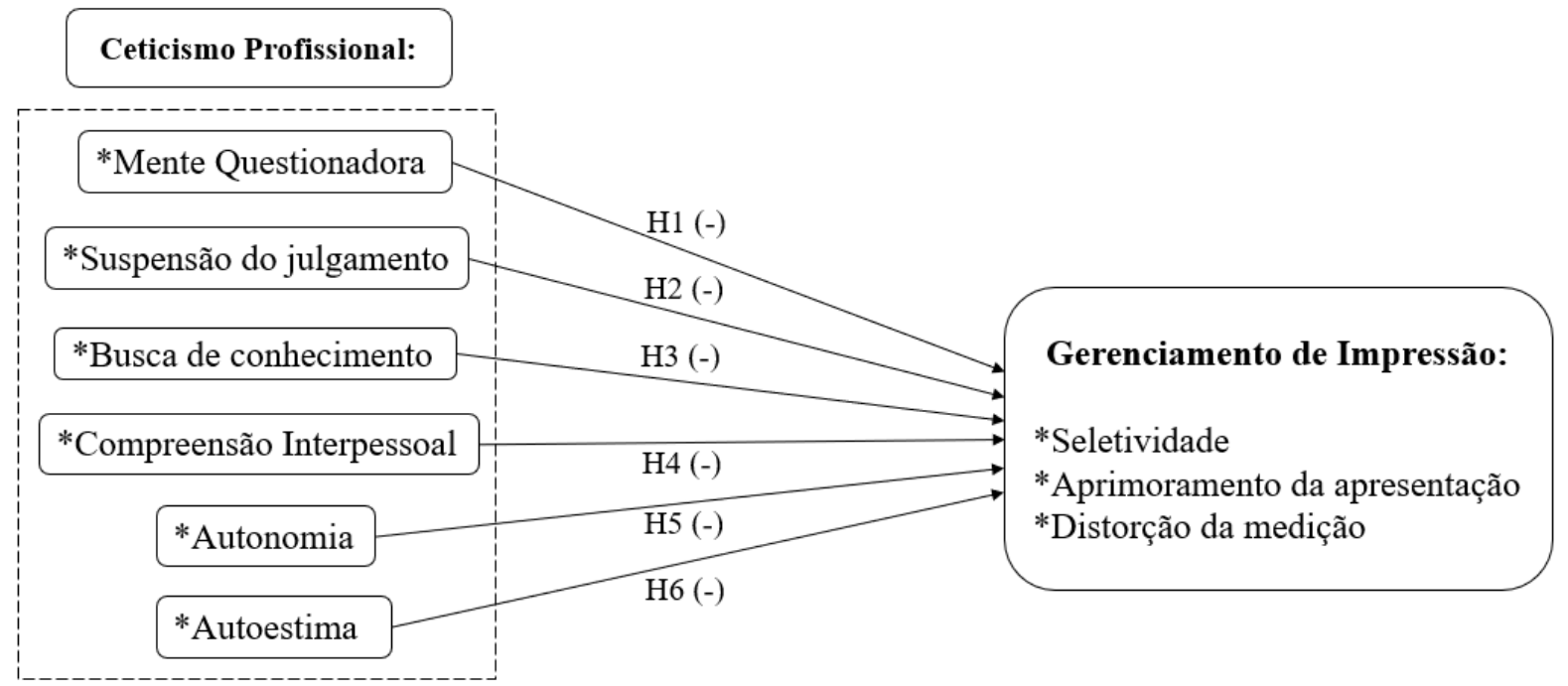

Fonte: Elaborado pelos autores. 
Influência do Ceticismo Profissional no Gerenciamento de Impressão da Divulgação da Informação Contábil

Conforme a Figura 1, as hipóteses deste estudo propõem uma relação negativa entre as variáveis independentes (ceticismo profissional) e as variáveis dependentes (gerenciamento de impressão).

\section{PROCEDIMENTOS METODOLÓGICOS}

No que tange à abordagem do problema, o trabalho caracteriza-se como quantitativo, quanto o objetivo como pesquisa descritiva e em relação ao procedimento como de levantamento ou survey. A população do estudo é formada pelos acadêmicos do curso de Ciências Contábeis de duas Universidades Públicas do estado de Santa Catarina, totalizando 416 indivíduos. A amostra abarcou 201 respondentes, representando 48,3\% da população. A aplicação do estudo junto aos estudantes foi solicitada e autorizada pelos coordenadores dos cursos. Antes da aplicação do questionário, os participantes receberam e assinaram o Termo de Consentimento, que esclarecia a possibilidade de desistência da colaboração da pesquisa e a garantia de anonimato. Em relação a coleta dos dados, o questionário foi dividido em duas etapas, a primeira etapa ocorreu de forma presencial, dividida em duas seções, com o objetivo de caracterizar os respondentes e medir o nível de ceticismo profissional. A segunda etapa foi elaborada em meio eletrônico no GoogleDocs ${ }^{\circledR}$ e o link da pesquisa foi enviado por e-mail e WhatsApp ${ }^{\circledR}$ para os respondentes da primeira etapa. O questionário da segunda etapa possuía o objetivo de mensurar o nível de gerenciamento de impressão nas variáveis de seletividade, aprimoramento de divulgação e distorção da medição. Os questionários foram aplicados no período de 29 de agosto de 2018 a 30 de setembro de 2018. O questionário se encontra na íntegra no Apêndice do estudo.

A Tabela 1 apresenta as variáveis utilizadas para identificar o nível de ceticismo profissional e o gerenciamento de impressão da divulgação de informações, conforme revisão de literatura.

Tabela 1 - Constructo da pesquisa

\begin{tabular}{|c|c|c|c|}
\hline Variável & Subvariáveis & Mensuração & Autores \\
\hline \multicolumn{4}{|l|}{ Dependente } \\
\hline \multirow{3}{*}{$\begin{array}{l}\text { Gerenciamento } \\
\text { de Impressão }\end{array}$} & Seletividade (SELE) & $\begin{array}{l}\text { 1. Série temporal com todas as informações. } \\
\text { 2. Série temporal com período selecionado. }\end{array}$ & \multirow{3}{*}{$\begin{array}{l}\text { Beattie e Jones } \\
\text { (2000) e } \\
\text { Cardoso, Leite } \\
\text { e Aquino } \\
\text { (2018) }\end{array}$} \\
\hline & $\begin{array}{c}\text { Aprimoramento da } \\
\text { apresentação (APRI) }\end{array}$ & $\begin{array}{l}\text { 1. Gráfico com prejuízos sucessivos em cor } \\
\text { vermelha. } \\
\text { 2. Gráfico com prejuízos sucessivos em cor } \\
\text { azul. }\end{array}$ & \\
\hline & Distorção da Medição (DIST) & $\begin{array}{l}\text { 1. Gráfico com escala de } \mathrm{R} \$ 0,00 \text { a } \mathrm{R} \$ \\
80.000,00 \text {. } \\
\text { 2. Gráfico com escala de } \mathrm{R} \$ 0,00 \text { a } \mathrm{R} \$ \\
40.000,00\end{array}$ & \\
\hline \multicolumn{4}{|l|}{ Independente } \\
\hline \multirow{6}{*}{$\begin{array}{l}\text { Ceticismo } \\
\text { Profissional }\end{array}$} & Mente Questionadora (MQ) & 5 questões de forma Likert & \multirow{6}{*}{$\begin{array}{c}\text { Hurtt (2010); } \\
\text { Farag e Elias } \\
\text { (2012); Popova } \\
\text { (2012); } \\
\text { Royaee, } \\
\text { Nezhad e } \\
\text { Azinfar (2013) }\end{array}$} \\
\hline & $\begin{array}{l}\text { Suspensão do Julgamento } \\
\text { (SJ) }\end{array}$ & 5 questões de forma Likert & \\
\hline & Busca de Conhecimento (BC) & 5 questões de forma Likert & \\
\hline & $\begin{array}{l}\text { Compreensão Interpessoal } \\
(\mathrm{CI})\end{array}$ & 5 questões de forma Likert & \\
\hline & Autonomia (AUTO) & 5 questões de forma Likert & \\
\hline & Autoestima (AUTE) & 5 questões de forma Likert & \\
\hline
\end{tabular}

Fonte: Elaborado pelos autores.

Conforme Tabela 1, a variável ceticismo foi mensurada a partir de questões elaboradas por Hurtt (2010). Cada questão utiliza uma escala com pontuação de 1 a 6 pontos de acordo com a relevância de cada questão. Ao desenvolver a escala, Hurtt (2010) identificou seis traços 
Influência do Ceticismo Profissional no Gerenciamento de Impressão da Divulgação da Informação Contábil

pertencentes ao ceticismo, mente questionadora (MQ), suspensão do julgamento (SP), busca por conhecimento (BC), compreensão interpessoal (CI), autoestima (AUTE) e autonomia (AUTO).

O escore de ceticismo profissional foi calculado por meio da soma dos valores atribuídos a cada questão ( 1 a 6 pontos) e o inverso da soma (valor atribuído - 7) nas questões de significado reverso (questões $1,10,11,16,17,19,25,26)$. O escore foi feito individualmente para cada característica do ceticismo profissional, sendo que cada característica poderia alcançar valores entre 5 e 30 pontos e o escore geral de ceticismo profissional foi realizado pela soma dos escores individuais de cada característica, podendo alcançar valores entre 30 e 180 pontos.

Posteriormente para verificar o gerenciamento de impressão nas variáveis seletividade, distorção de medição e aprimoramento da apresentação, foi elaborado um questionário contendo dois gráficos para cada variável, sendo um de apresentação da informação não gerenciada e o outro gerenciada. Os respondentes atribuíram uma nota de desempenho para cada gráfico, atribuído a cada empresa (A, B, C, D, E e F). A nota possuía uma escala de 0 a 10 , sendo que 0 significava muito ruim e 10 muito bom.

A elaboração dos gráficos se deu conforme o conceito de cada técnica de gerenciamento de impressão. Em seguida, foi calculado o nível do gerenciamento de impressão nos gráficos, por meio da diferença da nota atribuída ao gráfico manipulado versus o gráfico neutro. Deste modo, uma diferença positiva significa que houve gerenciamento, pois, o indivíduo atribuiu uma nota maior ao gráfico manipulado do que ao neutro e uma diferença nula ou negativa não indica gerenciamento de impressão.

Em virtude dos constructos do ceticismo profissional e do gerenciamento de impressão já terem sido testados no Brasil, não se realizou o pré-teste. A escala de Hurtt (2010) sobre o ceticismo profissional foi aplicado nos estudos de Haveroth (2017), Sampaio (2017), Rohenkohl (2017), Cunha et al. (2019) e Marçal e Alberton (2020), sendo um instrumento reconhecido para mensuração do ceticismo profissional. $\mathrm{O}$ constructo do gerenciamento de impressão foi utilizado no estudo de Cardoso, Leite e Aquino (2018), sendo um dos poucos estudos a operacionalizar um cenário para o gerenciamento de impressão a partir de gráficos, que é o foco do estudo.

Por fim, os dados foram analisados a partir da estatística descritiva e da regressão OLS por meio do software SPSS ${ }^{\circledR}$. Para a regressão se utilizou os seguintes modelos, Eq. (1), Eq. (2) e Eq. (3):

$$
\begin{aligned}
& \text { SELE }=\beta_{0}+\beta_{1} \mathrm{MQ}+\beta_{2} \mathrm{SJ}+\beta_{3} \mathrm{BC}+\beta_{4} \mathrm{CI}+\beta_{5} \mathrm{AUTO}+\beta_{6} \mathrm{AUTE}+\varepsilon \\
& \text { APRI }=\beta_{0}+\beta_{1} \mathrm{MQ}+\beta_{2} \mathrm{SJ}+\beta_{3} \mathrm{BC}+\beta_{4} \mathrm{CI}+\beta_{5} \mathrm{AUTO}+\beta_{6} \mathrm{AUTE}+\varepsilon \\
& \text { DIST }=\beta_{0}+\beta_{1} \mathrm{MQ}+\beta_{2} \mathrm{SJ}+\beta_{3} \mathrm{BC}+\beta_{4} \mathrm{CI}+\beta_{5} \mathrm{AUTO}+\beta_{6} \mathrm{AUTE}+\varepsilon
\end{aligned}
$$

Foram observados alguns pressupostos para a regressão OLS como o da normalidade, ausência de multicolinearidade, ausência de heterocedasticidade e ausência de autocorrelação (FÁVERO et al., 2009). 
Matthes, Adam, Tene e Cunha (2020)

Influência do Ceticismo Profissional no Gerenciamento de Impressão da Divulgação da Informação Contábil

\section{ANÁLISE DOS RESULTADOS}

Quanto a análise descritiva dos dados, nota-se uma predominância do sexo feminino com $60,7 \%$ (122). A idade dos entrevistados corresponde em sua maioria a estudantes de até 20 anos, totalizando 48,3\% (97) dos respondentes. No que se refere à ocupação profissional dos indivíduos, 49,8\% trabalham em alguma área relacionada com a contabilidade, o que corresponde 44,8\% (100) dos respondentes.

A Tabela 2 apresenta a análise descritiva quanto os níveis de ceticismo profissional obtidos a partir do instrumento de Hurtt (2010).

Tabela 2 - Análise Descritiva dos Níveis de Ceticismo Profissional

\begin{tabular}{l|c|c|c|c|c}
\hline \multicolumn{1}{c|}{ Variáveis } & Mínimo & Máximo & Média & $\begin{array}{c}\text { Desvio- } \\
\text { Padrão }\end{array}$ & Variância \\
\hline Mente Questionadora (MQ) & 10,00 & 30,00 & 20,34 & 3,94 & 15,51 \\
\hline Suspensão de Julgamento (SJ) & 8,00 & 30,00 & 23,57 & 3,97 & 15,74 \\
\hline Busca de Conhecimento (BC) & 12,00 & 30,00 & 24,63 & 4,47 & 19,94 \\
\hline Compreensão Interpessoal (CI) & 5,00 & 30,00 & 20,79 & 4,45 & 19,84 \\
\hline Autonomia (AUTO) & 6,00 & 30,00 & 21,43 & 4,94 & 24,43 \\
\hline Autoestima (AUTE) & 5,00 & 30,00 & 20,23 & 4,71 & 22,22 \\
\hline Ceticismo (CP) & 87,00 & 170,00 & 131,00 & 15,94 & 253,94 \\
\hline
\end{tabular}

Fonte: Dados da pesquisa.

De acordo com a Tabela 2, observa-se que a escala geral de ceticismo é 131 pontos em média, a qual pode chegar no máximo o valor de 180 . Percebe-se também que o indivíduo com o nível menor de ceticismo profissional foi de 87 pontos e o maior 170 pontos. Assim, indicase elevado nível de ceticismo entre os participantes da pesquisa, conforme (FARAG; ELIAS, 2012; HURTT, 2010; HAVEROTH, 2017; SAMPAIO, 2017).

Farag e Elias (2012) obtiveram uma escala média de 134,91 pontos de ceticismo profissional e Hurtt (2010), obteve 132,70 pontos, ambos estudos foram realizados com alunos dos Estados Unidos. No Brasil, contudo, o instrumento de Hurtt (2010) foi aplicado com auditores por Haveroth (2017) na qual obteve uma média de 145,50 pontos e Sampaio (2017) com 145,47 pontos. Portanto, percebe-se que os níveis de ceticismo dos estudantes encontramse próximos dos 130-135 pontos, porém são inferiores aos de auditores, que se encontram próximos a 145 pontos, o que se julga adequado dada toda a experiência que auditores possuem em relação a estudantes de Ciências Contábeis.

Dentre as características, as que mais obtiveram destaques foram a Suspensão de Julgamento e Busca de Conhecimento, 23,57 e 24,63 pontos respectivamente. Esses achados corroboram com os de Farag e Elias (2012), nos quais foram obtidos 23,81 pontos para Suspensão de Julgamento e 23,88 pontos para Busca de Conhecimento, ambas características também se sobressaíram sobre as demais, Mente Questionadora obteve 21,17 pontos, Compreensão Interpessoal obteve 22,23 pontos, Autonomia obteve 20,235 pontos e Autoestima obteve 23,26 pontos.

A Tabela 3 apresenta os resultados da análise em relação aos indivíduos frente aos gráficos gerenciados versus gráficos não gerenciados.

Tabela 3 - Quantidade de respondentes influenciados por variável de gerenciamento de impressão

\begin{tabular}{l|c|c}
\hline \multicolumn{1}{c|}{ Tipo de Gerenciamento } & Frequência & Percentual \\
\hline Seletividade & 181 & $90,0 \%$ \\
\hline Aprimoramento de Divulgação & 41 & $20,4 \%$ \\
\hline Distorção de Medição & 86 & $42,6 \%$ \\
\hline
\end{tabular}

Fonte: Dados da pesquisa.

A partir da Tabela 3, evidencia-se que a seletividade da informação, influenciou em $90 \%$ a nota atribuída pelos respondentes, ou seja, 181 indivíduos atribuíram uma nota maior ao gráfico com gerenciamento do que o gráfico neutro. A distorção de medição influenciou em 
Influência do Ceticismo Profissional no Gerenciamento de Impressão da Divulgação da Informação Contábil

42,6\% dos respondentes, sendo que 86 participantes atribuíram uma maior nota ao gráfico com distorção de escala do que ao gráfico neutro. Por último, nota-se que o aprimoramento de apresentação não surtiu tanto efeito nos respondentes em comparação com os outros tipos de gerenciamento, em que, apenas 20,4\% dos participantes, 41 indivíduos, atribuíram uma melhor nota ao gráfico com realce de cores em contrapartida ao neutro.

Portanto, nota-se que a seletividade foi a principal técnica que influenciou o julgamento dos indivíduos, seguida pela distorção de medição. Porém, o aprimoramento de informação foi o menos efetivo.

A Tabela 4 demonstra a análise descritiva do gerenciamento de impressão pela técnica da seletividade.

Tabela 4 - Análise Descritiva Gerenciamento de Impressão por Seletividade

\begin{tabular}{c|c|c|c|c|c|c}
\hline \multirow{2}{*}{ Respondentes } & Gráfico & Tipo & Média & Mediana & Moda & $\begin{array}{c}\text { Desvio } \\
\text { Padrão }\end{array}$ \\
\hline \multirow{2}{*}{ Todos } & Empresa B & Sem Gerenciamento & 6,5 & 7,0 & 7,0 & 1,3 \\
\cline { 2 - 7 } & Empresa D & Com Gerenciamento & 8,8 & 9,0 & 9,0 & 1,1 \\
\hline \multirow{2}{*}{ Gerenciados } & Empresa B & Sem Gerenciamento & 6,4 & 7,0 & 7,0 & 1,2 \\
\cline { 2 - 7 } & Empresa D & Com Gerenciamento & 9,0 & 9,0 & 9,0 & 0,9 \\
\hline \multirow{2}{*}{ Não-Gerenciados } & Empresa B & Sem Gerenciamento & 7,5 & 8,0 & 8,0 & 1,2 \\
\cline { 2 - 7 } & Empresa D & Com Gerenciamento & 7,1 & 7,0 & 8,0 & 1,5 \\
\hline
\end{tabular}

Fonte: Dados da pesquisa.

A partir da análise da Tabela 4, nota-se que num nível geral, o gráfico seletivo recebeu uma nota mais alta do que o neutro, sendo que a diferença de nota atribuída pelos indivíduos que não sofreram gerenciamento de impressão para os gráficos foi de apenas -12,5\%, contrária à amostra geral de $35,3 \%$ e aos indivíduos gerenciados $40,6 \%$.

A Tabela 5 demonstra a análise descritiva do gerenciamento de impressão pela técnica do aprimoramento da apresentação.

Tabela 5 - Análise Descritiva dos Gráficos pelo aprimoramento da apresentação

\begin{tabular}{c|c|c|c|c|c|c}
\hline \multirow{2}{*}{ Respondentes } & \multirow{2}{*}{ Gráfico } & Tipo & \multirow{2}{*}{ Média } & \multirow{2}{*}{ Mediana } & \multirow{2}{*}{ Moda } & $\begin{array}{c}\text { Desvio } \\
\text { Padrão }\end{array}$ \\
\hline \multirow{2}{*}{ Todos } & Empresa A & S/ Gerenciamento & 3,3 & 3,0 & 3,0 & 2,2 \\
\cline { 2 - 7 } & Empresa F & C/ Gerenciamento & 2,9 & 3,0 & 3,0 & 1,9 \\
\hline \multirow{2}{*}{ Gerenciados } & Empresa A & S/ Gerenciamento & 2,7 & 3,0 & 3,0 & 2,0 \\
\cline { 2 - 7 } & Empresa F & C/ Gerenciamento & 3,2 & 3,0 & 5,0 & 1,9 \\
\hline \multirow{2}{*}{$\begin{array}{c}\text { Não- } \\
\text { Gerenciados }\end{array}$} & Empresa A & S/ Gerenciamento & 3,6 & 3,5 & 5,0 & 2,2 \\
\cline { 2 - 8 } & Empresa F & C/ Gerenciamento & 2,7 & 3,0 & 2,0 & 1,9 \\
\hline
\end{tabular}

Fonte: Dados da pesquisa.

A Tabela 5 evidencia o resultado do aprimoramento de impressão nos indivíduos, podendo-se verificar que o aprimoramento de apresentação não surtiu muitos efeitos na análise dos respondentes, pois afetou apenas $20,4 \%$ da amostra e as notas atribuídas por estes resultaram em uma diferença de $18,5 \%$. Porém, chama-se atenção o fato de que os indivíduos que não sofreram gerenciamento de impressão, em média atribuíram uma nota pior ao gráfico gerenciado $(2,7)$ do que para o normal $(3,6)$.

Na Tabela 6, demonstra-se a análise descritiva do gerenciamento de impressão pela técnica da distorção da medição. 
Matthes, Adam, Tene e Cunha (2020)

Influência do Ceticismo Profissional no Gerenciamento de Impressão da Divulgação da Informação Contábil

Tabela 6 - Análise Descritiva dos Gráficos pela distorção da medição

\begin{tabular}{c|c|c|c|c|c|c}
\hline \multirow{2}{*}{ Respondentes } & Gráfico & Tipo & Média & Mediana & Moda & $\begin{array}{c}\text { Desvio } \\
\text { Padrão }\end{array}$ \\
\hline \multirow{2}{*}{ Todos } & Empresa C & S/ Gerenciamento & 8,3 & 9,0 & 9,0 & 1,6 \\
\cline { 2 - 7 } & Empresa E & C/ Gerenciamento & 8,9 & 9,0 & 10,0 & 1,3 \\
\hline \multirow{2}{*}{ Gerenciados } & Empresa C & S/ Gerenciamento & 7,3 & 8,0 & 7,0 & 1,6 \\
\cline { 2 - 7 } & Empresa E & C/ Gerenciamento & 9,4 & 10,0 & 10,0 & 1,0 \\
\hline $\begin{array}{c}\text { Não- } \\
\text { Gerenciados }\end{array}$ & Empresa C & S/ Gerenciamento & 9,0 & 9,0 & 10,0 & 1,1 \\
\cline { 2 - 7 } & Empresa E & C/ Gerenciamento & 8,6 & 9,0 & 10,0 & 1,4 \\
\hline
\end{tabular}

Fonte: Dados da pesquisa.

Conforme elencado na Tabela 6, verificou-se que os indivíduos no geral atribuíram uma nota muito próxima ao gráfico neutro e gerenciado, diferença de apenas $7,2 \%$. Por outro lado, os indivíduos que tiveram o julgamento influenciado pela distorção, atribuíram uma nota em média $34,3 \%$ maior ao gráfico gerenciado e os indivíduos que não foram influenciados, atribuíram uma nota 4,5\% menor ao gráfico gerenciado.

Quanto a análise dos resultados pela regressão linear múltipla, a Tabela 7 apresenta a influência do ceticismo profissional na seletividade.

Tabela 7 - Influência do Ceticismo Profissional na Seletividade

\begin{tabular}{l|c|c|c}
\hline Variáveis & Coef. & Sig. & VIF \\
\hline (Constante) & 2,464 & 0,009 & \\
\hline Mente Questionadora (MQ) & 0,038 & 0,259 & 1,398 \\
\hline Suspensão de Julgamento (SJ) & 0,003 & 0,925 & 1,375 \\
\hline Busca de Conhecimento (BC) & $-0,032$ & 0,303 & 1,544 \\
\hline Compreensão Interpessoal (CI) & 0,009 & 0,734 & 1,235 \\
\hline Autonomia (AUTO) & 0,007 & 0,782 & 1,112 \\
\hline Autoestima (AUTE) & $-0,030$ & 0,232 & 1,104 \\
\hline Durbin Watson & & 2,190 & \\
\hline $\mathrm{R}^{2}$ equação: & \multicolumn{3}{|c}{0,015} \\
\hline Sig equação: & \multicolumn{2}{|c}{0,807} & \\
\hline
\end{tabular}

* Significativo até $10 \%$.

Fonte: Dados da pesquisa.

De acordo com Tabela 7 pode-se observar que o modelo de regressão atendeu aos pressupostos da análise multivariada de Durbin Watson $(2,19)$ e colinearidade (VIF < 10 para todas as variáveis). Porém, o modelo de regressão que prevê o nível de seletividade por meio do ceticismo profissional não se demonstrou estatisticamente significativo.

Com o intuito de aprofundar a relação do modelo, realizou-se uma nova regressão, desta vez considerando-se apenas os indivíduos que sofreram influência no seu julgamento pela seletividade, apresentando na Tabela 8 o resultado.

Tabela 81 - Influência do Ceticismo Profissional na Seletividade Manipulada

\begin{tabular}{|c|c|c|c|}
\hline Variáveis & Coef. & Sig. & VIF \\
\hline (Constante) & 3,067 & 0,000 & \\
\hline Mente Questionadora (MQ) & 0,008 & 0,784 & 1,439 \\
\hline Suspensão de Julgamento (SJ) & $-0,005$ & 0,857 & 1,437 \\
\hline Busca de Conhecimento (BC) & $-0,002$ & 0,931 & 1,617 \\
\hline Compreensão Interpessoal (CI) & $-0,011$ & 0,650 & 1,232 \\
\hline Autonomia (AUTO) & 0,001 & 0,969 & 1,103 \\
\hline Autoestima (AUTE) & $-0,014$ & 0,523 & 1,122 \\
\hline Durbin Watson & \multicolumn{3}{|c|}{1,894} \\
\hline $\mathrm{R}^{2}$ equação: & \multicolumn{3}{|c|}{0,005} \\
\hline Sig equação: & \multicolumn{3}{|c|}{0,989} \\
\hline
\end{tabular}

* Significativo até $10 \%$.

Fonte: Dados da pesquisa.

Novamente, não foi encontrada relevância entre os dois modelos, pois de acordo com a Tabela 8 pode-se observar que não houve significância do modelo $(0,989)$ e a explicação ficou 
Influência do Ceticismo Profissional no Gerenciamento de Impressão da Divulgação da Informação Contábil

em torno de apenas 0,005 para com a seletividade manipulada. Portanto, observou-se que as características de ceticismo não influenciam de forma significativa o gerenciamento de impressão pela seletividade.

A Tabela 9 apresenta a influência das características do ceticismo profissional no aprimoramento de apresentação da divulgação das informações.

Tabela 9 - Influência do Ceticismo Profissional no Aprimoramento da Divulgação

\begin{tabular}{l|c|c|c}
\hline \multicolumn{1}{c|}{ Variáveis } & Coef. & Sig. & VIF \\
\hline (Constante) & 0,857 & 0,178 & 1,000 \\
\hline Mente Questionadora (MQ) & $-0,06$ & 0,049 & 1,232 \\
\hline \multicolumn{3}{|c|}{ Variáveis excluídas da regressão } \\
\hline Suspensão de Julgamento (SJ) & $-0,021$ & 0,789 & 1,186 \\
\hline Busca de Conhecimento (BC) & $-0,072$ & 0,346 & 1,041 \\
\hline Compreensão Interpessoal (CI) & $-0,099$ & 0,169 & 1,067 \\
\hline Autonomia (AUTO) & 0,037 & 0,608 & 0,059 \\
\hline Autoestima (AUTE) & $-0,028$ & 2,013 & 0,019 \\
\hline Durbin Watson & & $0,049 *$ & \\
\hline $\mathrm{R}^{2}$ equação: & \multicolumn{3}{c}{}
\end{tabular}

* Significativo até $10 \%$.

Fonte: Dados da pesquisa.

Observa-se de acordo com a Tabela 9 que não foram encontrados níveis de significância no modelo como um todo. Porém houve significância do modelo ao considerar apenas as características Mente Questionadora $(0,049)$ e excluir as demais e a explicação desta de 1,9\%. Utilizou-se nesta etapa a regressão por etapas a fim de demonstrar somente a variável significativa que por hora demonstra a significância no modelo também. Constatou-se que a variável Mente Questionadora demonstrou influência significativa para redução $(-0,06)$ do aprimoramento da divulgação, o que infere que quanto maior a Mente Questionadora, menor o aprimoramento da divulgação.

A característica mente questionadora diz respeito ao indivíduo com perfil questionador, busca constante por informações, análise cuidadosa dos dados e consideração por todos os pontos antes da tomada de decisão (NELSON, 2009). Portanto, quanto maior esta característica no indivíduo, menor tende a ser a influência do aprimoramento da divulgação, pois este apresentou correlação negativa com a Mente Questionadora $(-0,06)$. Realizou-se ainda uma nova regressão para considerar apenas os indivíduos que sofreram influência no seu julgamento pelo aprimoramento de divulgação. Esta análise foi chamada de aprimoramento da divulgação manipulado. Com base nisto, verifica-se a Tabela 10.

Tabela 10 - Influência do Ceticismo Profissional no Aprimoramento da Divulgação Manipulado

\begin{tabular}{|c|c|c|c|}
\hline Variáveis & Coef. & Sig. & VIF \\
\hline (Constante) & 3,595 & 0,039 & \\
\hline Mente Questionadora (MQ) & $-0,001$ & 0,983 & 1,909 \\
\hline Suspensão de Julgamento (SJ) & 0,067 & 0,205 & 1,825 \\
\hline Busca de Conhecimento (BC) & $-0,040$ & 0,404 & 1,332 \\
\hline Compreensão Interpessoal (CI) & $-0,035$ & 0,506 & 1,756 \\
\hline Autonomia (AUTO) & $-0,048$ & 0,219 & 1,340 \\
\hline Autoestima (AUTE) & $-0,032$ & 0,424 & 1,282 \\
\hline Durbin Watson & \multicolumn{3}{|c|}{2,160} \\
\hline $\mathrm{R}^{2}$ equação: & \multicolumn{3}{|c|}{0,196} \\
\hline Sig equação: & \multicolumn{3}{|c|}{0,251} \\
\hline
\end{tabular}

* Significativo até $10 \%$.

Fonte: Dados da pesquisa.

De acordo com a Tabela 10 pode-se verificar que não houve significância no modelo $(0,251)$ e a explicação deste foi em torno de $19,6 \%$. Ademais, nenhuma das variáveis do ceticismo profissional testadas demonstrou influência significativa neste modelo. 
Matthes, Adam, Tene e Cunha (2020)

Influência do Ceticismo Profissional no Gerenciamento de Impressão da Divulgação da Informação Contábil

A Tabela 11 apresenta a influência das características do ceticismo profissional na distorção de medição da divulgação das informações.

Tabela 11 - Influência do Ceticismo Profissional na Distorção de Medição

\begin{tabular}{|c|c|c|c|}
\hline Variáveis & Coef. & Sig. & VIF \\
\hline (Constante) & 3,427 & 0,000 & \\
\hline Mente Questionadora (MQ) & $-0,057$ & 0,097 & 1,398 \\
\hline Suspensão de Julgamento (SJ) & $-0,032$ & 0,346 & 1,375 \\
\hline Busca de Conhecimento (BC) & $-0,034$ & 0,286 & 1,544 \\
\hline Compreensão Interpessoal (CI) & 0,036 & 0,201 & 1,235 \\
\hline Autonomia (AUTO) & $-0,016$ & 0,514 & 1,112 \\
\hline Autoestima (AUTE) & $-0,024$ & 0,337 & 1,104 \\
\hline Durbin Watson & \multicolumn{3}{|c|}{2,243} \\
\hline $\mathrm{R}^{2}$ equação: & \multicolumn{3}{|c|}{0,0712} \\
\hline Sig equação: & \multicolumn{3}{|c|}{$0,025^{*}$} \\
\hline
\end{tabular}

* Significativo até $10 \%$.

Fonte: Dados da pesquisa.

A Tabela 11 demonstra que houve significância do modelo acima $(0,025)$ e a explicação deste é de 71,2\%. As variáveis Suspensão de Julgamento, Busca de Conhecimento, Conhecimento Interpessoal, Autonomia e Autoestima não apresentaram significância, ou seja, não predizem o julgamento sobre a distorção de medição. Porém a variável Mente Questionadora apresentou influência significativa $(0,097)$ e de forma negativa $(-0,057)$, o que indica que quanto maior a Mente Questionadora menor a ação da distorção de medição.

Não obstante, foi realizada uma nova regressão, levando em consideração apenas os indivíduos que sofreram influência no seu julgamento pela distorção de medição. Este modelo foi denominado de distorção de medição manipulado, exposto na Tabela 12.

Tabela 12 - Influência do Ceticismo Profissional na Distorção de Medição Manipulado

\begin{tabular}{|c|c|c|c|}
\hline Variáveis & Coef. & Sig. & VIF \\
\hline (Constante) & 3,900 & 0,003 & \\
\hline Mente Questionadora (MQ) & $-0,124$ & 0,006 & 1,644 \\
\hline Suspensão de Julgamento (SJ) & 0,040 & 0,356 & 1,355 \\
\hline Busca de Conhecimento (BC) & $-0,013$ & 0,706 & 1,485 \\
\hline Compreensão Interpessoal (CI) & $-0,000$ & 0,995 & 1,284 \\
\hline Autonomia (AUTO) & $-0,012$ & 0,686 & 1,176 \\
\hline Autoestima & 0,016 & 0,662 & 1,217 \\
\hline Durbin Watson & \multicolumn{3}{|c|}{2,137} \\
\hline $\mathrm{R}^{2}$ equação: & \multicolumn{3}{|c|}{0,128} \\
\hline Sig equação: & \multicolumn{3}{|c|}{$0,085^{*}$} \\
\hline
\end{tabular}

* Significativo até $10 \%$.

Fonte: Dados da pesquisa.

De acordo com a Tabela 12 pode-se observar significância do modelo $(0,085)$ e explicação deste em torno de $12,8 \%$. A única variável que se demonstrou significativa e com influência na distorção de medição manipulado foi Mente Questionadora, com relação negativa, o que indica que quanto maior a Mente Questionadora menor é a distorção de medição. Tal resultado significa que, quanto maiores os níveis de Mente Questionadora no indivíduo, menor tende a ser a influência da distorção de medição sobre o julgamento deste.

Com base de comparação com outros estudos, Royaee, Nezhad e Azinfar (2013), encontraram evidências de que o nível de ceticismo profissional influencia a tomada de decisão do indivíduo, principalmente quanto às variáveis mente questionadora, compreensão interpessoal, autoconfiança e autonomia.

Porém, não foram encontrados estudos que pudessem serem utilizados como comparação entre os resultados que relacionassem os dois temas, apenas com outras variáveis. Dentre estes, foi encontrada relação de incremento entre o ceticismo profissional e a capacidade de avaliar o risco de detecção de fraudes (AMINUDIN; SURYANDARI, 2016; IDAWATI; 
Matthes, Adam, Tene e Cunha (2020)

Influência do Ceticismo Profissional no Gerenciamento de Impressão da Divulgação da Informação Contábil

GUNAWAN, 2015), a percepção ética quanto a formas de manipulação de resultados também apresentou relação com o ceticismo profissional (FARAG; ELIAS, 2012).

A Tabela 13 apresenta o resumo das hipóteses com a descrição e resultado de cada uma.

Tabela 13 - Resumo Hipóteses

\begin{tabular}{c|c|c}
\hline Hipótese & Descrição & Resultado \\
\hline Hipótese 1 & Mente questionadora $\rightarrow$ Gerenciamento de Impressão & Suportada \\
\hline Hipótese 2 & Suspensão do Julgamento $\rightarrow$ Gerenciamento de Impressão & Não suportada \\
\hline Hipótese 3 & Busca de Conhecimento $\rightarrow$ Gerenciamento de Impressão & Não suportada \\
\hline Hipótese 4 & Compreensão Interpessoal $\rightarrow$ Gerenciamento de Impressão & Não suportada \\
\hline Hipótese 5 & Autonomia $\rightarrow$ Gerenciamento de Impressão & Não suportada \\
\hline Hipótese 6 & Autoestima $\rightarrow$ Gerenciamento de Impressão & Não suportada \\
\hline
\end{tabular}

Fonte: Dados da pesquisa.

Conforme apresenta a Tabela 13, apenas a Hipótese 1 foi suportada, indicando que há uma relação negativa entre a característica do ceticismo profissional mente questionadora e o gerenciamento de impressão da divulgação da informação contábil. Desta forma, quanto maior o nível da característica mente questionadora num indivíduo, menor a possibilidade de ser influenciado pelas técnicas de gerenciamento de impressão.

\section{CONCLUSÃO E RECOMENDAÇÕES DE PESQUISA}

O estudo teve por objetivo analisar a influência do ceticismo profissional no gerenciamento de impressão da divulgação da informação contábil. Os resultados apresentam que a seletividade da informação, influenciou $90 \%$ das notas atribuídas pelos respondentes, que avaliaram o gráfico seletivo melhor do que o neutro. A distorção de medição influenciou em $42,6 \%$ dos respondentes e o aprimoramento de apresentação surtiu efeito apenas em $20,4 \%$ dos participantes, os quais, atribuíram uma melhor nota ao gráfico com realce de cores em contrapartida ao neutro.

O ceticismo profissional não demonstrou influência no julgamento do indivíduo sobre informações divulgadas seletivamente. No que diz respeito ao aprimoramento de divulgação e a distorção de medição, houve relação significativa e negativa para a característica mente questionadora. Portanto, o estudo obteve indícios de que o nível do ceticismo profissional e suas características de um modo geral não são capazes de influenciar o julgamento do indivíduo acerca das técnicas de gerenciamento de impressão, apenas a característica mente questionadora.

Assim, quanto maior o nível da característica mente questionadora de um indivíduo, menor tende a ser a influência das técnicas do aprimoramento de divulgação e da distorção de medição sobre o seu julgamento. Provavelmente, apresentar um perfil questionador reduz a possibilidade de ser influenciado pelo uso de cores ou variação de medidas e escalas, pois busca e analisa com maior cuidado as informações antes de tomar uma decisão, ou seja, não segue a primeira impressão. A seletividade, por sua vez, é mais difícil de ser identificada, mesmo com o perfil mais cético, visto que a informação divulgada é um recorte da situação da empresa.

Os resultados do estudo são relevantes ao indicarem que o ceticismo, mais precisamente a característica da mente questionadora, pode ser utilizada para minimizar os efeitos das técnicas de gerenciamento de impressão (aprimoramento de divulgação e distorção de medição) que podem ser implementadas na divulgação das informações contábeis. Além disso, os resultados evidenciam que as três técnicas de gerenciamento de impressão (seletividade, aprimoramento de divulgação e distorção de medição) podem influenciar o julgamento dos indivíduos, principalmente a seletividade. Desta maneira, enfatiza-se a necessidade de órgãos reguladores atentarem a forma que as empresas estão utilizando os artifícios de apresentação 
Influência do Ceticismo Profissional no Gerenciamento de Impressão da Divulgação da Informação Contábil

no processo de disclosure, para que os usuários das informações contábeis não sejam prejudicados.

Para pesquisas futuras, sugere-se aplicar o estudo para uma amostra maior de participantes, principalmente com profissionais de mercado, como contadores, auditores e investidores, para analisar se a experiência desse público influencia a relação entre ceticismo e gerenciamento de impressão. Ademais, os efeitos visuais (uso de gráficos) não são as únicas técnicas para gerenciar a impressão dos indivíduos, por isso, sugere-se analisar o ceticismo profissional com outras técnicas e formas de gerenciamento de impressão, tais como a manipulação sintática que ocorre por meio das narrativas utilizadas nos relatórios contábeis e de administração. Por fim, outras características podem ser investigadas com o gerenciamento de impressão, como a personalidade e estado de humor dos indivíduos.

\section{REFERÊNCIAS}

AMERICAN INSTITUTE OF CERTIFIED PUBLIC ACCOUNTANTS. AU-C Section 200: Overall Objectives of the Independent Auditor and the Conduct of an Audit in Accordance with Generally Accepted Auditing Standards. Nova Iorque: AICPA, 2017.

AMINUDIN, M. R.; SURYANDARI, D. Factors Affecting Auditor's Ability in Detecting Fraud through Professional Skepticism. Accounting Analysis Journal, v. 5, p. 344-351, 2016.

ARANTES, V. A.; GUSMÃO, I. B.; COSTA, M. C. Análise do relatório de guidance em empresas investigadas pela Polícia Federal: exame sob a perspectiva do gerenciamento de impressões. Revista de Contabilidade e Organizações, v. 13, p. 1-13, 2019.

BARKEMEYER, R.; COMYNS, B.; FIGGE, F.; NAPOLITANO, G. CEO statements in sustainability reports: Substantive information or background noise? Accounting Forum, v. 38, p. 241-257, 2014.

BEATTIE, V.; JONES, M. J. Impression Management: The Case of Inter-Country Financial Graphs. International Accounting, Auditing \& Taxation, v. 9, n. 2, 2000.

CARDOSO, R. L.; LEITE, R. O.; AQUINO, A. C. B. The effect of cognitive reflection on the efficacy of impression management: an experimental analysis with financial analysts. Accounting Auditing \& Accountability Journal, v. 31, n. 6, p. 1668-1690, 2018. CARMICHAEL, D.; CRAIG, J. J. Proposal to say the 'F' word in auditing standards. The CPA Journal, v. 66, p. 22, 1996.

CHO, C. H.; MICHELON, G.; PATTEN, D. Impression Management in Sustainability Reports: An Empirical Investigation of the Use of Graphs. Accounting and the Public Interest American Accounting Association, v. 12, p. 16-37, 2012.

CLEVELAND, W. S.; MCGILL, R. Graphical perception and graphical methods for analyzing scientific data. Science, v. 229, n. 4716, p. 828-33, 1985.

COELHO, C. M. P.; NIYAMA, J. K.; RODRIGUES, J. M. Análise da qualidade da informação contábil frente a implementação dos IFRS: uma pesquisa baseada nos periódicos internacionais (1999 a 2010). Sociedade, Contabilidade e Gestão, v. 6, n. 2, p. 7-20, 2011.

COMITÊ DE PRONUNCIAMENTOS CONTÁBEIS. CPC 00 - R1: Estrutura Conceitual para Elaboração e Divulgação de Relatório Contábil-Financeiro - DF. Brasília: CPC, 2011. 
Influência do Ceticismo Profissional no Gerenciamento de Impressão da Divulgação da Informação Contábil

CONSELHO FEDERAL DE CONTABILIDADE. NBC TA 200 - R1: Objetivos Gerais do Auditor Indepentende. Brasília: CFC, 2016.

COURTIS, J. K. Corporate report obfuscation: Artefact or phenomenon? British Accounting Review, v. 36, n. 3, p. 291-312, 2004.

CUNHA, P. R. da; SILVA, C. T. da; PEYERL, D. A.; HAVEROTH, J. Influência dos traços de personalidade no ceticismo profissional de auditores independentes. Revista de Contabilidade e Organizações, v. 13, p. 1-14, 2019.

FARAG, M. S.; ELIAS, R. Z. The Impact of Accounting Students' Professional Skepticism on their Ethical Perception of Earnings Management. Research on Professional Responsibility and Ethics in Accounting, v. 16, p. 185-200, 2012.

FARAG, M. S.; ELIAS, R. Z. The relationship between accounting students' personality, professional skepticism and anticipatory socialization. Accounting Education, v. 25, p. 124138, 2016.

FÁVERO, L. P.; BELFIORE, P.; SILVA, F. L.; CHAN, B. L. Análise de dados: modelagem multivariada para tomar decisões. Rio de Janeiro, Elsevier, 2009.

GODFREY, J.; MATHER, P.; RAMSAY, A. Earnings and impression management in financial reports: The case of CEO changes. Abacus, v. 39, n. 1, p. 95-123, 2003.

HAVEROTH, J. Ceticismo Profissional e Estresse Ocupacional de Auditores

Independentes. 2017. Dissertação (Mestrado em Ciências Contábeis) - Universidade Regional de Blumenau, Blumenau, 2017.

HURTT, R. K. Development of a Scale to Measure Professional Skepticism. Auditing: A Journal of Practice \& Theory, v. 29, n. 1, p. 149-171, 2011.

HOOGHIEMSTRA, R. Corporate communication and impression management - new perspectives on why companies engage in corporate social reporting. Journal of business ethics, v. 27, p. 55-68, 2000.

IDAWATI, W.; GUNAWAN, A. Effect of competence, independence, and professional skepticism against ability to detect fraud action in audit assignment. Serial Journal IJABER, v. 13, n. 1, p. 5123-5138, 2015.

JONES, M. J. The nature, use and impression management of graphs in social and environmental accounting. Accounting Forum. v. 35, p. 75-89, 2011.

MARÇAL, R. R.; ALBERTON, L. Relação entre os Traços Sombrios de Personalidade e o Ceticismo Profissional dos Auditores Independentes. Revista de Educação e Pesquisa em Contabilidade, v. 14, n. 4, p. 480-500, 2020.

MELO, P. C.; GRAHAM, D. J.; NOLAND, R. B. A meta-analysis of estimates of urban agglomeration economies. Regional Science \& Urban Economics, v. 39 n. 3, p. 332-

$342,2009$.

MERKL-DAVIES, D. M.; BRENNAN, N. M. A conceptual framework of impression management: new insights from psychology, sociology and critical perspectives. Accounting and Business Research, v. 41 n. 5, p. 415-437, 2011. 
Influência do Ceticismo Profissional no Gerenciamento de Impressão da Divulgação da Informação Contábil

MERKL-DAVIES, D. M.; BRENNAN, N. M.; MCLEAY, S. J. Impression management and retrospective sense-making incorporate narratives: a social psychology perspective.

Accounting, Auditing \& Accountability Journal, v. 24, n. 3, p. 315-344, 2011.

PAYNE, E.; RAMSAY, R. "Fraud risk assessments and auditors' professional skepticism". Managerial Auditing Journal, v. 20, n. 3, p. 321-330, 2005.

NELSON, M. A model and literature review of professional skepticism in auditing.

Auditing: A Journal of Practice and Theory, v. 2, n. 2, p. 1-34, 2009.

NOLDER, C. J.; KADOUS, K. Grounding the professional skepticism construct in mindset and attitude theory: A way forward. Accounting, Organizations and Society, v. 67, p. 1-14, 2018 .

PENNINGTON, R.; TUTTLE, B. Managing impressions using distorted graphs of income and earnings per share: The role of memory. International Journal of Accounting Information Systems, v. 10, p. 25-45, 2009.

PONTE, V. M. R.; OLIVEIRA, M. C. A prática da evidenciação de informações avançadas e não obrigatórias nas demonstrações contábeis das empresas brasileiras. Revista

Contabilidade \& Finanças - USP, v. 15, n. 36, p. 7-20, 2004.

POPOVA, V. Exploration of skepticism, client-specific experiences, and audit judgments.

Managerial Auditing Journal, v. 28, p. 140-160, 2012.

PRYKE, S. R. Is red an innate or learned signal of aggression and intimidation? Animal

Behaviour, v. 78, n. 2, p. 393-398, 2009.

REZAEE, Z. Causes, consequences, and deterence of financial statement fraud. Critical Perspectives on Accounting, v. 16, n. 1, p. 277-298, 2005.

ROHENKOHL, L. B. Relação do Traço Cético e da Satisfação no Trabalho no Comportamento Cético de Auditores Independentes. 2017. 117 f. Dissertação (Mestrado em Ciências Contábeis) - Universidade Regional de Blumenau, Blumenau, 2017.

ROYAEE, A. R.; NEZHAD, A. Y.; AZINFAR, K. Relationship between Skepticism and Decision Making in Audit. World Applied Sciences Journal, v. 28, n. 11, p. 1609-1617, 2013.

SAMPAIO, G. L. Influência do Estado de Humor na Relação entre o Ceticismo

Profissional e o Julgamento e Tomada de Decisão de Auditores Independentes. 2017. 141

f. Dissertação (Mestrado em Ciências Contábeis) - Universidade Regional de Blumenau, Blumenau, 2017.

STOUGH, C. L. Greek Skepticism. Berkeley, CA: University of California Press, 1969.

VARGAS, L. H. F; ALMEIDA, J. E. F. de; MARIA JÚNIOR, E. Lucro e prejuízo sob a perspectiva da administração: como os resultados são apresentados nos relatórios de administração? Revista de Educação e Pesquisa em Contabilidade (REPeC), v. 8, n. 4, p. 351-368, 2014.

YANG, J. H.; LIU, S. Accounting narratives and impression management on social media. Accounting and Business Research, v. 47, n. 6, p. 673-694, 2017. 
Influência do Ceticismo Profissional no Gerenciamento de Impressão da Divulgação da Informação Contábil

\section{APÊNDICE - QUESTIONÁRIO DA PESQUISA}

\section{INSTRUÇÕES:}

O questionário está elaborado em duas partes. No primeiro momento tem-se como objetivo caracterizar e classificar cada respondente de acordo com suas características pessoais. A segunda parte do questionário, com apenas 6 questões, será enviada e respondida por meios eletrônicos. Por isso, peço por gentileza que deixe seus contatos para poder enviá-lo tanto a segunda parte do questionário quanto os resultados da pesquisa.

E-mail:

Telefone:

\section{CARACTERIZAÇÃO DOS RESPONDENTES}

1.1 Sexo:
( ) Feminino
( ) Masculino

1.2 Informe a sua idade em anos completos: anos de idade.

\subsection{Curso:}

( ) Ciências Contábeis

\subsection{Semestre:}
( ) $1^{\circ}\left(\right.$ ) $2^{\circ}$
( ) $3^{\circ}$
( ) $4^{\circ}$
( ) $5^{\circ}$
( ) $6^{\circ}$
( ) $7^{\circ}$ ( ) $8^{\circ}$

\subsection{Trabalha?}

( ) Sim ( ) Não

1.6 Se sim, em qual área?

( ) Contabilidade

( ) Departamento fiscal

( ) Departamento pessoal / Recursos Humanos

( ) Departamento financeiro

( ) Outro

1.7 Informe em anos o tempo que você atua na área: anos

\section{INSTRUMENTO DE HURTT (2010) PARA MENSURAÇÃO DO NÍVEL DE CETICISMO PROFISSIONAL}

Por favor, selecione a resposta que indique como você geralmente se sente. Não há respostas certas ou erradas. Não demore muito tempo em qualquer declaração. A escala de respostas varia entre 1- Discordo totalmente e 6- Concordo totalmente.

\begin{tabular}{|c|l|c|c|c|c|c|c|}
\hline N. & 1- DISCORDO TOTALMENTE e 6- CONCORDO TOTALMENTE. & \multicolumn{4}{|c|}{ Grau de Concordância } \\
\hline 1 & Muitas vezes aceito as explicações de outras pessoas sem pensar muito. & 1 & 2 & 3 & 4 & 6 \\
\hline 2 & Eu me sinto bem comigo mesmo (a). & 1 & 2 & 3 & 4 & 5 & 6 \\
\hline 3 & $\begin{array}{l}\text { Eu espero para decidir sobre as questões até que eu possa obter mais } \\
\text { informações. }\end{array}$ & 1 & 2 & 3 & 4 & 5 & 6 \\
\hline 4 & A perspectiva de aprender me anima. & 1 & 2 & 3 & 4 & 5 & 6 \\
\hline 5 & $\begin{array}{l}\text { Sou interessado (a) no motivo pelo qual as pessoas se comportam de } \\
\text { determinada maneira. }\end{array}$ & 1 & 2 & 3 & 4 & 5 & 6 \\
\hline 6 & Sou confiante em minhas habilidades. & 1 & 2 & 3 & 4 & 5 & 6 \\
\hline 7 & $\begin{array}{l}\text { Muitas vezes eu rejeito declarações a menos que eu tenha provas de que elas } \\
\text { são verdadeiras. }\end{array}$ & 1 & 2 & 3 & 4 & 5 & 6 \\
\hline 8 & Descobrir novas informações é divertido. & 1 & 2 & 3 & 4 & 5 & 6 \\
\hline
\end{tabular}


Matthes, Adam, Tene e Cunha (2020)

Influência do Ceticismo Profissional no Gerenciamento de Impressão da Divulgação da Informação Contábil

\begin{tabular}{|c|c|c|c|c|c|c|c|}
\hline 9 & Levo o tempo que for necessário para tomar decisões. & 1 & 2 & 3 & 4 & 5 & 6 \\
\hline 10 & Eu tendo a aceitar imediatamente o que outras pessoas me dizem. & 1 & 2 & 3 & 4 & 5 & 6 \\
\hline 11 & O comportamento de outras pessoas não me interessa. & 1 & 2 & 3 & 4 & 5 & 6 \\
\hline 12 & Sou autoconfiante. & 1 & 2 & 3 & 4 & 5 & 6 \\
\hline 13 & Meus amigos me dizem que costumo questionar coisas que eu vejo ou escuto. & 1 & 2 & 3 & 4 & 5 & 6 \\
\hline 14 & Eu gosto de entender a razão do comportamento de outras pessoas. & 1 & 2 & 3 & 4 & 5 & 6 \\
\hline 15 & Acho que aprender é emocionante. & 1 & 2 & 3 & 4 & 5 & 6 \\
\hline 16 & $\begin{array}{l}\text { Eu costumo aceitar as coisas que vejo, leio ou escuto pela primeira impressão } \\
\text { que tenho. }\end{array}$ & 1 & 2 & 3 & 4 & 5 & 6 \\
\hline 17 & Eu não tenho certeza das minhas opiniões. & 1 & 2 & 3 & 4 & 5 & 6 \\
\hline 18 & Eu normalmente percebo inconsistências nas explicações. & 1 & 2 & 3 & 4 & 5 & 6 \\
\hline 19 & Na maioria das vezes eu concordo com o que os outros do meu grupo pensam. & 1 & 2 & 3 & 4 & 5 & 6 \\
\hline 20 & Eu não gosto de ter que tomar decisões rapidamente. & 1 & 2 & 3 & 4 & 5 & 6 \\
\hline 21 & Tenho confiança em mim mesmo (a). & 1 & 2 & 3 & 4 & 5 & 6 \\
\hline 22 & Eu não gosto de decidir até que eu olhe toda a informação já disponível. & 1 & 2 & 3 & 4 & 5 & 6 \\
\hline 23 & Eu gosto de procurar por conhecimento. & 1 & 2 & 3 & 4 & 5 & 6 \\
\hline 24 & Frequentemente questiono coisas que vejo ou escuto. & 1 & 2 & 3 & 4 & 5 & 6 \\
\hline 25 & É fácil para outras pessoas me convencer. & 1 & 2 & 3 & 4 & 5 & 6 \\
\hline 26 & Eu raramente questiono por que as pessoas se comportam de certa maneira. & 1 & 2 & 3 & 4 & 5 & 6 \\
\hline 27 & $\begin{array}{l}\text { Gosto de garantir que considerei a maior parte das informações disponíveis } \\
\text { antes de tomar uma decisão. }\end{array}$ & 1 & 2 & 3 & 4 & 5 & 6 \\
\hline 28 & Eu gosto de tentar determinar se o que eu leio ou escuto é verdade. & 1 & 2 & 3 & 4 & 5 & 6 \\
\hline 29 & Eu gosto de aprender. & 1 & 2 & 3 & 4 & 5 & 6 \\
\hline 30 & As ações que as pessoas tomam e as razões para essas ações são fascinantes. & 1 & 2 & 3 & 4 & 5 & 6 \\
\hline
\end{tabular}

\section{GERENCIAMENTO DE IMPRESSÃO}

Agora você é convidado a avaliar o desempenho de algumas empresas com base exclusivamente nos gráficos apresentados.

\section{Empresa A}

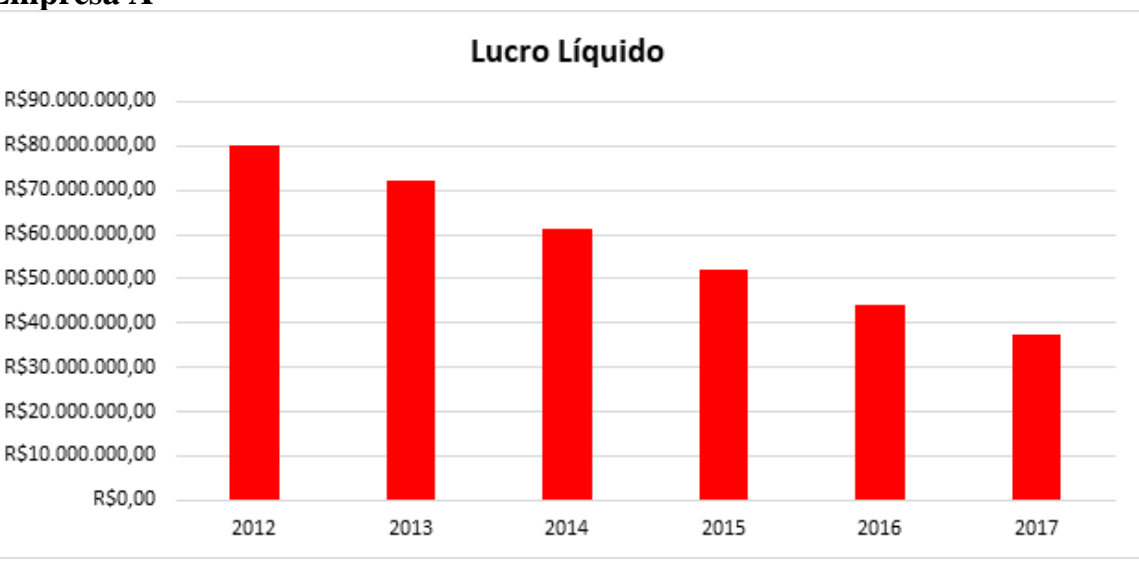

* Como você avaliaria o desempenho da Empresa A tomando como base exclusivamente o gráfico da Empresa A?

Atribua uma nota entre 0 (muito ruim) e 10 (muito bom) 
Matthes, Adam, Tene e Cunha (2020)

Influência do Ceticismo Profissional no Gerenciamento de Impressão da Divulgação da Informação Contábil

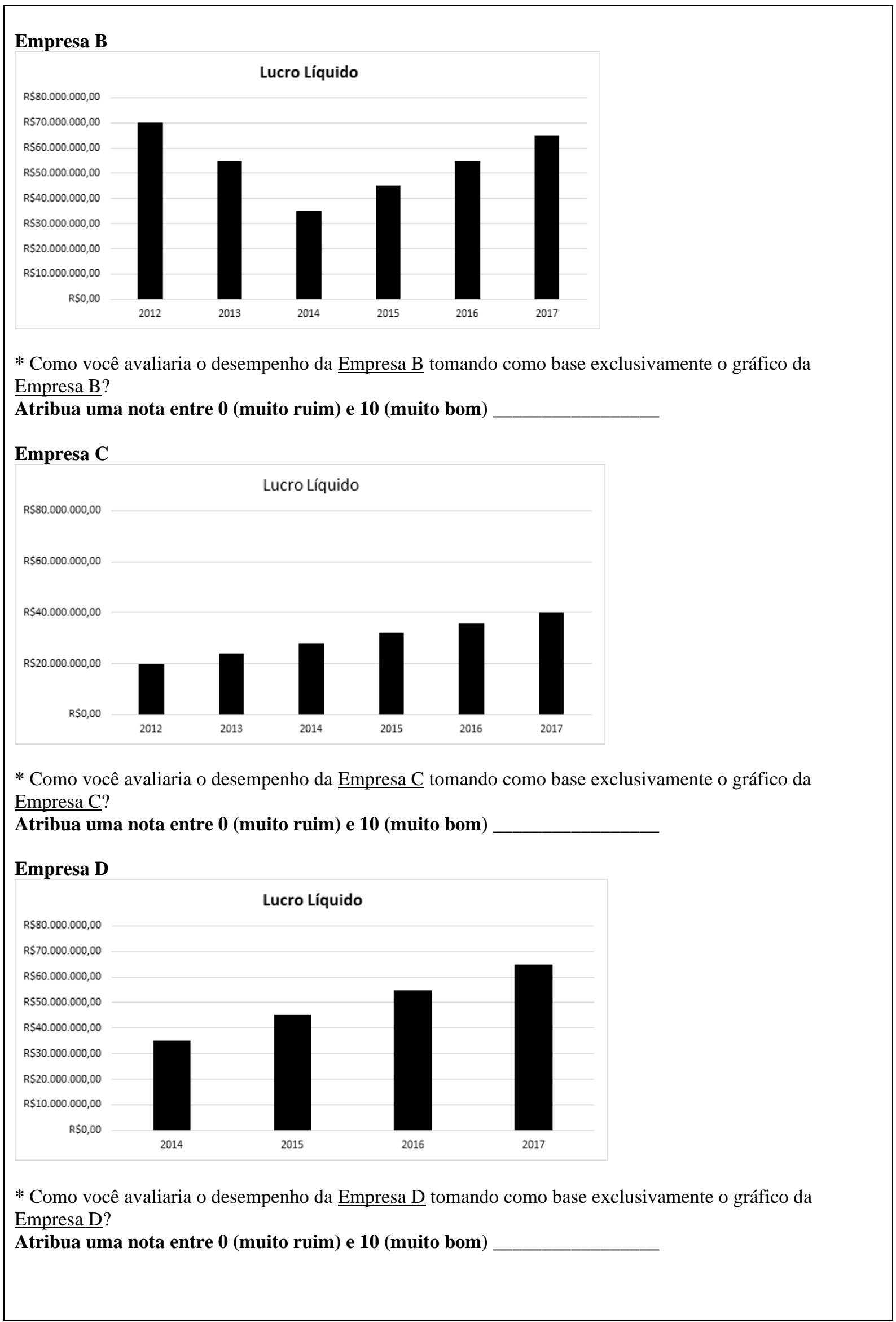


Matthes, Adam, Tene e Cunha (2020)

Influência do Ceticismo Profissional no Gerenciamento de Impressão da Divulgação da Informação Contábil

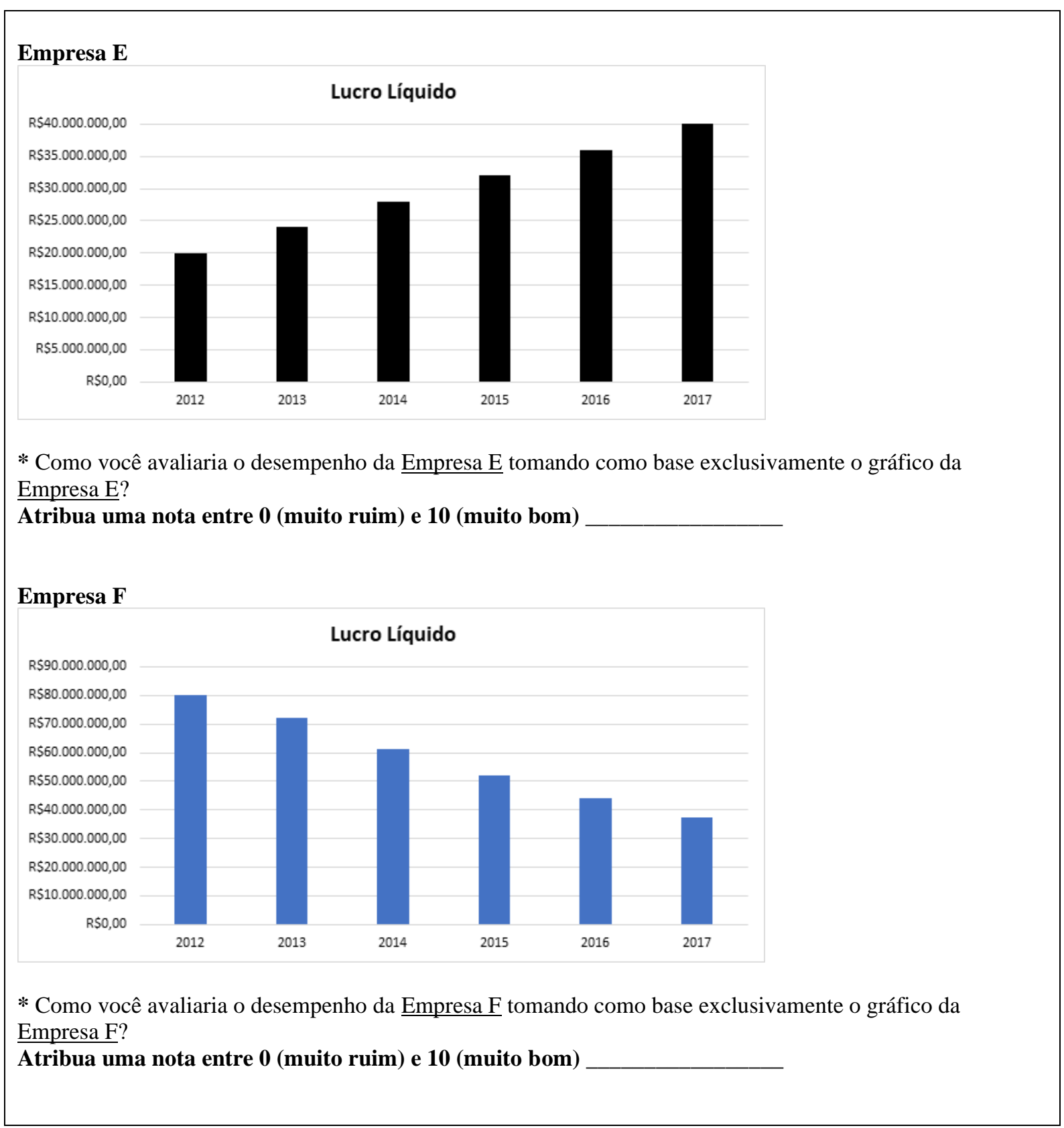

